\title{
A Dollar for Your Thoughts: Feedback-Conditional Rebates on eBay
}

\author{
Luís Cabral \\ New York University and CEPR \\ Lingfang (Ivy) Li \\ Shanghai University of Finance and Economics
}

July 2012

\begin{abstract}
We run a series of controlled field experiments on eBay where buyers are rewarded for providing feedback. Our results suggest that the feedback rate increases when a rebate is given, though the effect is small. Moreover, the nature of buyer feedback is influenced by rewards: buyers are more likely to give positive feedback following a high-quality transaction (fast shipping) and less likely to give negative feedback following a lowquality transaction (slow shipping). In sum, you can buy feedback but you cannot buy unbiased feedback.
\end{abstract}

Key words: feedback, rebates, experiment

Cabral: W R Berkley Term Professor of Economics, Stern School of Business, New York University; SP-SP Research Fellow; and Research Fellow, CEPR (London); lcabral@stern.nyu.edu. Li: Associate Professor, School of Economics; Director, Center for Mechanism Design and Economics of Information, Institute for Advanced Research, Shanghai University of Finance and Economics; Key Laboratory of Mathematical Economics (SUFE), Ministry of Education, Shanghai 200433, China; lingfangivy.li@gmail.com. The authors are in alphabetical order and the corresponding author's email is lingfangivy.li@gmail.com.

We thank Matthew Beachy and Adam Zhanqing Hong for their excellent research assistance. Li gratefully acknowledges the financial support of Shanghai Pujiang program (grant \#10PGC040), Shanghai Leading Academic Discipline Project (Project Number: B801), and the 211 Project for Shanghai University of Finance and Economics. 


\section{Introduction}

Customer feedback is an important component of a firm's strategy. Given the degree of seller anonymity in online trade platforms, customer feedback is particularly important in this context. Studies of eBay buyer behavior have shown that a seller's past experience, as measured by the number and quality of past feedback postings, is an important determinant of a seller's success, both in terms of number of bidders and size of bids (Cabral, 2012).

Given the importance of customer feedback, sellers have an interest in encouraging buyers to post a review, in particular a positive review. Similarly, online trade platform owners have an interest in fostering transactions feedback to the extent that this improves the seller reputation mechanism and thus increases buyer confidence.

In this paper, we consider one possible seller strategy: to provide buyers with a rebate conditional on rating the quality of their transaction. By establishing two eBay sellers who auction the same homogeneous good (a USB pen drive), we are able to run a series of controlled field experiments where we vary the degree to which buyers are rewarded for feedback, as well as a component of the quality of the transaction (speed of shipment).

Our experiments address a series of research questions. First of all, we inquire whether paying for feedback induces buyers to give more feedback. We show that feedback frequency increases when it is rewarded, but the effect is relatively small. A second important research question is whether the nature of buyer feedback is altered by the fact a reward is offered by the seller. It is possible that feedback rebates work as "bribes," whereby buyers feel compelled to provide better feedback than their experience would lead them to. We show that, when the product sold is shipped slowly, some buyers give negative feedback. However, the frequency of such negative feedback is lower the greater the feedback reward, whereas the frequency of positive feedback is greater. In other words, feedback rewards leads to a considerable feedback bias.

Contrary to economic theory predictions, we show that feedback rewards have no effect on bidding behavior, either the number of bidders or the average bid. This can be explained by buyer myopia, inattention, or incredulity with respect to the sellers feedback reward offer.

On March 2012, China's leading online trade platform, Taobao, started a conditional feedback reward system, details of which are presented in Section 2. This development came to us as a surprise and was implemented well after we designed and ran our field experiment. Although it refers to a different trade platform (Taobao as opposed to eBay) and was designed in a slightly 
different way, the new Taobao scheme provides additional motivation and relevance for our work.

- Related Literature. A growing theoretical and empirical literature shows that a seller's reputation history is an important determinant of a seller's success, especially in online markets. Relevant contributions include Shapiro (1983), Avery et al (1999), Dellarocas (2003), Bolton et al (2004), Houser and Wooders (2006), Jin and Kato (2006), Resnick et al (2006), Cabral and Hortaçsu (2010), Grosskopf and Sarin (2010). In online markets, reputation systems usually rely on voluntary feedback from involved parties. This creates a problem of public good underprovision, for which various solutions have been proposed. For example, Miller et al (2005) and Jurca and Faltings (2007) propose truth-eliciting incentive schemes to induce buyers to report and do so honestly. These mechanisms either require buyers or the market (e.g., eBay) to bear the reporting cost. Given the importance of customer feedback, sellers have an interest in encouraging buyers to post a review, so sellers may have more incentive to bear the reporting cost than buyers or the market.

Li (2010a) proposes a rebate mechanism in an online auction market: sellers have the option of committing by providing a rebate (not necessarily in monetary form) to cover the buyer's reporting cost, regardless of whether the feedback is positive or negative. In theory, this rebate mechanism plays a dual role of incentivizing buyers to leave feedback and providing a device for sellers to signal quality or effort to cooperate. In equilibrium, buyers will not buy from the sellers who do not choose the rebate option and incorporate the rebate amount into their bids.

$\mathrm{Li}$ and Xiao (2010) expand the rebate mechanism model to a listedprice market and conduct a laboratory experiment to examine the effect of the dollar rebate mechanism on market efficiency. They find that a seller's rebate offer increases buyers' propensity to report in good transactions but not in bad transactions; the dollar rebate does not affect the honesty of the feedback; and the sellers' rebate decisions affect the buyers' purchasing decisions by signaling the buyer about the sellers' cooperative.

Monetary incentives are not the only way of inducing the desired buyer behavior. For instance, Abeler et al (2010) find that apology is more effective than monetary incentives in making buyers withdraw their negative feedback on eBay. Chen et al (2010a) run a field experiment on MovieLens.com and find that effective personalized social information can increase the level of public goods provision. Using data collected from Yelp.com, Wang (2010) argues that social image and reviews' productivities are positively 
correlated. Alternative ways of motivating agents are also explored in the work of Bénabou and Tirole (2003), Ariely et al (2009), Chen at al (2010b).

In this paper, we run a field experiment on eBay to test one possible seller strategy: to provide buyers with a monetary rebate conditional on rating the quality of their transaction. We are interested in investigating whether paying for feedback induces buyers to give more feedback, whether buyers bid higher when there is a rebate, and most important, whether the nature of buyer feedback is altered by the fact a monetary reward is offered by the seller.

The paper is organized as follows. In the next section, we review the new Taobao feedback reward system. While our experiment was ran on eBay, we believe the Taobao system is sufficiently similar to our experiment to warrant a detailed description. In Section 3, we describe the experiment's design. The results are presented in two sections: Section 4 includes basic tabulations, whereas Section 5 includes regression results. Finally, Section 6 concludes the paper.

\section{The new Taobao feedback reward scheme}

As mentioned in the introduction, on March 2012 China's leading online trade platform, Taobao, started a conditional feedback reward system. This development came to us as a surprise and was implemented well after we designed and ran our field experiment. Although it refers to a different trade platform (Taobao as opposed to eBay) and was designed in a slightly different way, the new Taobao scheme provides additional motivation and relevance for our work. In this section, we describe Taobao and its reward system in greater detail.

Launched in 2003, Taobao Marketplace (www.taobao.com) is the most popular consumer-to-consumer (C2C) online marketplace in China with nearly 500 million registered users. ${ }^{1}$ On an average day, more than 60 million visitors have access to more than 800 million product listings; on an average minute, 48 thousands products are sold. By the end of 2011, the peak daily transaction value was 4.38 billion RMB; and Taobao's market share was estimated to be $90.4 \%$ of a total Chinese C2C market sales of 59.4 billion RMB. ${ }^{2}$ According to Alexa and DoubleClick Ad Planner by Google site rankings, Taobao Marketplace is one of the world's top 20 most visited

1. Note these are not unique registered users. The number of Chinese online-shoppers was estimated to be 187 million in 2011, with a forecast of 363 million by 2015 .

2. http://ec.iresearch.cn/17/20120112/161325.shtml, accessed on June 24, 2012. 


\section{Figure 1}

Taobao's announcement of a new feedback reward system

The purpose of the "rebate for feedback" scheme is to:

- Increase the ratio of non-automatic to automatic seller ratings.

- Increase the quality of buyers' comments.

- Increase feedback for new products and thus reduce buyers' hesitation to purchase.

Benefits for buyers:

- Receive cash or a coupon as a reward for feedback.

- Become opinion leader as the display of their feedback is prioritized over others' feedback.

Benefits for sellers:

- Increase ratio of non-automatic to automatic ratings, thus attracting more future buyers.

- Increase buyer incentives to write detailed comments, thus increasing word-of-mouth marketing power.

Sellers can set:

- Reward for 1st high-quality feedback on newly listed products.

- Reward for any products, conditional on feedback being of high quality (and regardless of whether it is positive or negative).

Alternative form of rewards:

- Cash rewards.

- Discount coupon. 


\section{Figure 2}

Taobao.com page with feedback reward scheme

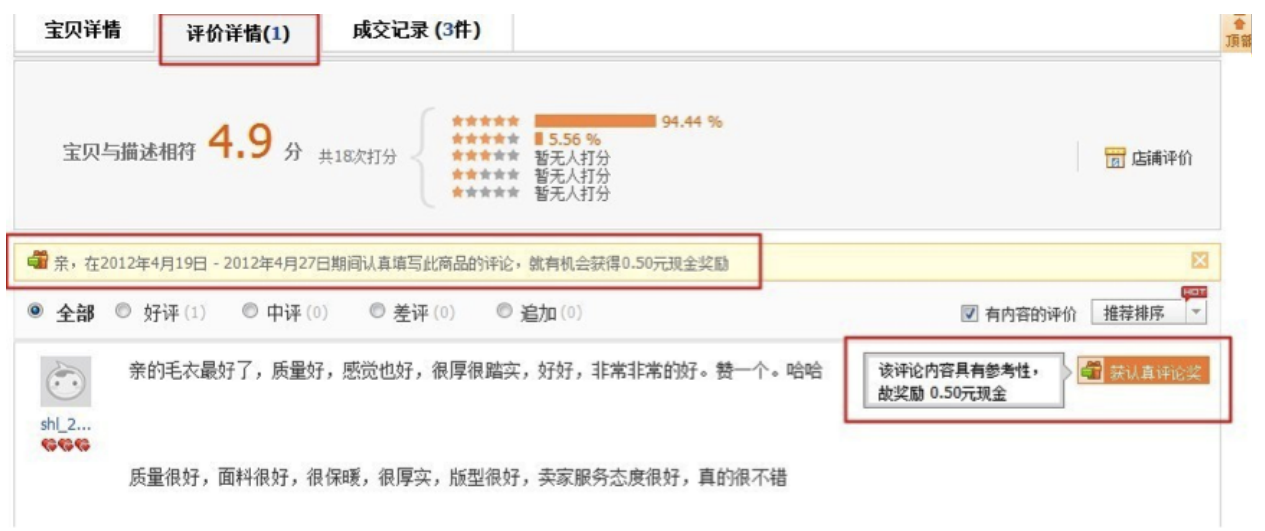

websites. $^{3}$

On March 1, 2012, Taobao launched a "Rebates for Feedback" seller option. If a seller chooses this option, the seller sets a rebate value (in the form of cash or a coupon) as part of their listings. Then Taobao makes sure the rebate is transferred from the seller's account to a buyer who leaves high-quality feedback. Feedback quality does not depends on whether the feedback is positive or negative; rather, it depends on how informative it is, a quality that Taobao measures with a machine algorithm that examines the comment's content and length, finds out whether key features of the item are mentioned, and so on.

Figure 1 shows Taobao's announcement of the new online service (our translation). Some notes are in order. One of the announced goals is to "increase the ratio of non-automatic ratings for sellers." To understand this, we note that in Taobao, if a buyer does not leave any feedback after the seller leaves feedback, the the system will help the buyer to leave an automatic positive rating to the seller. Second, the goal of increasing "the quality of buyers' comments" is related to Taobao's use of a machine algorithm to judge feedback quality. Finally, with respect to Taobao's role in helping the seller offer a rebate, the seller deposits a certain amount for a chosen period and Taobao freezes the deposit until the end of the period.

According to Taobao's own survey (published in March, 2012), 64.8\% of buyers think that they will be more willing to buy the items which have

3. Source: http://www.taobao.com/about/intro.php, accessed June 24, 2012. 
Figure 3

Kingston 2GB USB pen drive

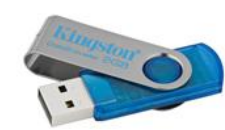

"rebate for feedback" feature, and $84.2 \%$ of buyers think that the "rebate for feedback" option will make them more likely to write detailed comments. ${ }^{4}$

Figure 2 shows a typical Taobao.com page with the new feedback reward scheme. ${ }^{5}$ The box just below the 4.9 score includes a feedback reminder. It reads

Dear customer, you will have a chance to get $0.50 \mathrm{RMB}$ reward, if you leave feedback conscientiously on the product from April 19-27, 2012.

The box on the lower right corner, in turn, includes a notice that this buyer has been awarded 0.50 RMB rebate for her feedback:

This comment is informative, so it is rewarded with 0.50 RMB.

\section{Field experiment design}

To examine the effects of monetary rebates on feedback behavior, we sold new Kingston 2GB USB pen drives on eBay (Figure 3). We chose to sell this particular product because it is a relatively standard product and it is sold by several other sellers. ${ }^{6}$ We chose to conduct the field experiment on eBay because it is the world's largest online auction market and has been the object of numerous complementary studies and experiments. ${ }^{7}$

4. http://bbs.taobao.com/catalog/thread/513886-256229600.htm, accessed June 24, 2012.

5. http://bbs.taobao.com/catalog/thread/513886-256229600.htm, accessed March 29, 2012.

6. One difficulty we we experienced was that Kingston stopped producing the $2 \mathrm{~GB}$ USB drives halfway throughout our experiment. We tried very hard to purchase the same model USB drives around the world so as to continue selling the same object.

7. See for example Dellarocas and Wood (2008); Brow and Morgan (2006); Resnick et al (2006); Brown et al (2010); Li (2010b). 
Table 1

Field experiment treatments

\begin{tabular}{|l|c|c|c|}
\hline & No Rebate & \$1 Rebate & \$2 Rebate \\
\hline Fast shipment & F0 & F1 & F2 \\
\hline Slow shipment & S0 & S1 & S2 \\
\hline
\end{tabular}

We registered two IDs on eBay and accumulated 75 positive feedback scores on each ID from buying and selling the Kingston pen drive. In this way, before beginning our experiment, we had two sellers with similar, established records. So as to avoid being identified as "experiment" sellers, we operated the two IDs on different days. Considering that there is a large number of sellers of the same object, our two IDs typically did not show on the same search page.

We created several treatments, with characteristics that vary along two dimensions. First, in different treatments we offered different levels of feedback rebate: $0, \$ 1$ and $\$ 2$ per feedback. We clearly stated the rebate amount of $\$ 1$ or $\$ 2$ in the item listing title. Specifically, we used the title "Brand New Kingston 2GB USB Flash Drive" for a no rebate listing and "Brand New Kingston 2GB USB Flash Drive ( $\$ 1$ rebate available)" for $\$ 1$ rebate listing (and the analogous title one for a $\$ 2$ rebate). In the listings with a rebate, we added the sentence

Rebate option. Your feedback is important to us; please give us your honest feedback and receive a $\$ 1$ credit in your Paypal account.

The second dimension that distinguishes different treatments is transaction quality. Specifically, we provided the identical USB drives with different speeds of shipment. For a "fast" transaction, we shipped the USB drive immediately upon receiving payment. For a "slow" transaction, we shipped the USB drive two weeks after sale.

Together, rebate value $(0,1,2)$ and shipment speed $(\mathrm{F}, \mathrm{S})$ create six different possibilities, as listed on Table 1. For example, treatment F1 corresponds to Fast shipping speed and a $\$ 1$ rebate, while treatment S0 corresponds to Slow shipping and no rebate offered.

Our experiment may be chronologically divided into 4 phases, as listed on Table 2. In Phase 1, our RA mistakenly offered a $\$ 1$ rebate right after receiving payment and before buyer feedback was received. For most of the paper, we do not include Phase 1's data into our analysis of conditional 
Table 2

Field experiment chronology

\begin{tabular}{|l|c|c|c|c|}
\hline Phase & Dates & Seller ID & Type & \# obs. \\
\hline Phase 1 & $2010 / 02 / 23-2010 / 05 / 08$ & 1 & F1*, F0 & 30 \\
\hline & & 2 & F1*, F0 & 30 \\
\hline Phase 2 & $2010 / 06 / 10-2010 / 08 / 19$ & 1 & F1, F0 & 30 \\
\hline & & 2 & F1, F0 & 30 \\
\hline Phase 3 & $2010 / 10 / 06-2011 / 01 / 11$ & 1 & F2, F0 & 30 \\
\hline & & 2 & S1, S0 & 31 \\
\hline
\end{tabular}

feedback rebates. However, we later return to the data from this phase. By the time we started Phase 2, both of our eBay IDs had 100+ positive feedback scores. In Phase 2 we offered the same feedback reward as in Phase 1, but we consistently made such rebate conditional on receiving buyer feedback. Thus Phase 2 corresponds to the F1 treatment (and F0 as well, for we only offered a feedback reward on some transactions).

In Phase 3, our two hitherto similar sellers took different paths. For seller ID1 we switched to an F2 treatment, that is, we increased the value of the rebate from $\$ 1$ to $\$ 2$. For seller ID2 we switched to a 2 -week shipment while keeping the $\$ 1$ rebate. Finally, in Phase 3 seller ID1 switched from fast to slow shipment, while keeping the $\$ 2$ rebate. $^{8}$

Table 3 displays basic descriptive statistics of the data generated by the experiment's various phases. We should also mention that, of the 205 transactions, in only 3 instances did the same buyer repeat a purchase from the same seller (there are a total of 17 repeat buyer sales in our data set, but most correspond to the same buyer purchasing from different sellers).

\section{Results: tabulation}

In this section, we present the main results from our experiment. We group them into several subsections. First, we investigate whether offering a feed-

\footnotetext{
8. Some buyers filed complaints with eBay regarding slow shipping by our seller ID2, so that it no longer met the minimal "detailed seller rating requirements" in the "Seller performance standards." As a result, ID2 was not operating during our Phase 4.

9. For feedback-received transactions only.
} 
Table 3

Descriptive statistics

\begin{tabular}{|c|c|c|c|c|c|}
\hline Variable & $\mathrm{N}$ & Mean & St dev & Min & Max \\
\hline Rebate & 201 & 0.687 & 0.719 & 0 & 2 \\
\hline Price & 201 & 3.823 & 1.573 & 1.04 & 11 \\
\hline Bidder count & 201 & 4.000 & 1.338 & 2 & 8 \\
\hline Bid count & 201 & 5.841 & 2.227 & 2 & 14 \\
\hline Bidder score & 201 & 350 & 700 & 0 & 6454 \\
\hline Bidder positive perc. & 201 & 0.983 & 0.107 & 0 & 1 \\
\hline Seller score & 201 & 112 & 22 & 75 & 151 \\
\hline Seller positive perc. & 201 & 0.998 & 0.007 & 0.956 & 1 \\
\hline Feedback & 201 & 0.682 & 0.555 & -1 & 1 \\
\hline Feedback lag (days) $)^{9}$ & 155 & 13.355 & 9.575 & 0 & 54 \\
\hline
\end{tabular}

back rebate induces buyers to give feedback more frequently. Next we look at the nature of feedback, that is, whether it becomes more favorable to the seller (conditional on transaction quality). Additional questions addressed by our study include the speed of buyer feedback and whether the expectation of a rebate changes bidding behavior.

A penny for your thoughts. The first research question in which we are interested is whether paying for feedback induces buyers to give feedback more frequently. Table 4 tabulates the frequency of feedback for different types of feedback policy. Restricting to fast shipment transactions, the percentage of transactions where feedback is given increases from $76.09 \%$ to $79.31 \%$ as we move from no rebate to a $\$ 1$ conditional rebate, and from $79.31 \%$ to $93.33 \%$ as we switch from a $\$ 1$ to $\$ 2$ conditional rebate.

In other words, our results suggest that feedback rewards induce higher feedback rates, though weakly: when we offer $\$ 1$ for customer feedback we don't observe a significant increase in the feedback rate; a $\$ 2$ reward however leads to an increase in the feedback rate that is economically and statistically significant.

- Can buy me love. The next question of interest is whether the nature of buyer feedback is altered by the fact that a reward is offered by the seller. In other words, we now inquire whether feedback rebates work as "bribes," whereby buyers feel compelled to provide better feedback than 
Table 4

Feedback behavior fast shipment transactions

\begin{tabular}{|l|r|r|r|r|r|r|r|}
\hline Feedback reward $\rightarrow$ & \multicolumn{3}{|c|}{ None } & \multicolumn{3}{|c|}{$\$ 1$} & \multicolumn{3}{|c|}{$\$ 2$} \\
\hline Outcome $\downarrow$ & $\#$ & $\%$ & $\#$ & $\%$ & $\#$ & $\%$ \\
\hline No feedback given & 11 & 24 & 6 & 21 & 1 & 7 \\
\hline Some feedback given & 35 & 76 & 23 & 79 & 14 & 93 \\
\hline Total & 44 & 100 & 29 & 100 & 15 & 100 \\
\hline Positive & 35 & 100 & 23 & 100 & 14 & 100 \\
\hline Negative & 0 & 0 & 0 & 0 & 0 & 0 \\
\hline Neutral & 0 & 0 & 0 & 0 & 0 & 0 \\
\hline
\end{tabular}

\section{Table 5}

Feedback behavior in slow shipment transactions

\begin{tabular}{|l|r|r|r|r|r|r|r|}
\hline Feedback reward $\rightarrow$ & \multicolumn{2}{|c|}{ None } & \multicolumn{2}{|c|}{$\$ 1$} & \multicolumn{2}{|c|}{$\$ 2$} \\
\hline Outcome $\downarrow$ & $\#$ & $\%$ & $\#$ & $\%$ & $\#$ & $\%$ \\
\hline No feedback given & 8 & 40 & 4 & 25 & 4 & 27 \\
\hline Some feedback given & 12 & 60 & 12 & 75 & 11 & 73 \\
\hline Total & 20 & 100 & 16 & 100 & 15 & 100 \\
\hline Positive & 7 & 58 & 9 & 75 & 10 & 91 \\
\hline Negative & 2 & 17 & 2 & 17 & 0 & 0 \\
\hline Neutral & 3 & 25 & 1 & 8 & 1 & 9 \\
\hline Negative or Neutral & 5 & 42 & 3 & 25 & 1 & 9 \\
\hline
\end{tabular}

their experience would lead them to.

Within the set of fast shipment transactions, our results are inconclusive because all feedback was positive. This limitation of our first treatments lead us to consider a second set of treatments. We purposely shipped our USB drive more slowly (exactly 14 days after receiving payment) and repeated the shift from no feedback to $\$ 1$ and $\$ 2$ conditional feedback (treatments S1 and $\mathrm{S} 2$, respectively).

Table 5 displays the results from this new treatment. As a preliminary question, we ask whether the lowering of service quality has any effect on the type of feedback received. The answer is clearly yes: whereas our fast-shipping transactions received exclusively positive feedback, our slowshipping transactions received 4 negative feedback messages (and 9 negative or neutral feedback messages). Using a t-test, we confirm that the negative 
feedback rate following a slow shipment transaction is statistically different from the negative feedback rate following a fast shipment transaction $(t=$ $-3.6) \cdot{ }^{10,11}$

Table 5 also shows that, as before, higher feedback rewards increase feedback frequency (from $60 \%$ to about $75 \%$ ). The novel test that Table 5 allows for is whether paying for feedback alters the nature of feedback. We observe that as we shift from no rebate to a $\$ 1$ or $\$ 2$ rebate the percentage of positive feedbacks within transactions with feedback increases.

In sum, you can buy feedback but you may not be able to buy unbiased feedback.

- The Avengers. Do feedback payments change the timing of feedback? To the extent that buyers have positive discount, we should expect that feedback rebates lead buyers to leave feedback quicker. To the extent that buyers want to reciprocate sellers for the kindness of providing feedback, we also expect quicker feedback when rebates are offered. ${ }^{12}$ Regarding the quality of the transaction, previous literature has shown that there is such a thing as demand for justice. ${ }^{13}$ In the present context, this would lead us to expect that delayed transactions create a greater demand for feedback (especially negative feedback), and that this would be given quicker.

Figure 4 presents summary data that addresses the above possibilities. We compute the variable "Days To Received Feedback" by computing the difference between "Date Feedback Left" and "Auction End Date." In the case of delayed auctions, we subtract an extra 14 days to account for the delay in shipping with respect to fast shipment transactions.

The results suggest that paying for feedback has little effect on the speed of feedback (though the sign of the change is in accordance to the theory prediction). Regarding transaction quality, we also observe an effect consistent

10. The same is true if we consider both neutral and negative feedback as negative feedback $(t=-5.6412)$.

11. As an aside, we note that the lack of negative feedback for Normal transactions should not be ascribed to "fear of retaliation," as several authors have previously argued. First, we (the seller) always give positive feedback promptly, so buyers have no reason to fear retaliation. Second, we do observe an increase in negative feedback as we reduce service quality.

12. See Fehr and Gächter( 2000b) and Dellarocas and Wood (2008) for more literature on positive Reciprocity.

13. See for example de Quervain et al. 2004; Fehr and Gächter, 2000a; Xiao and Houser, 2005. 


\section{Figure 4}

Average number of days before feedback is received

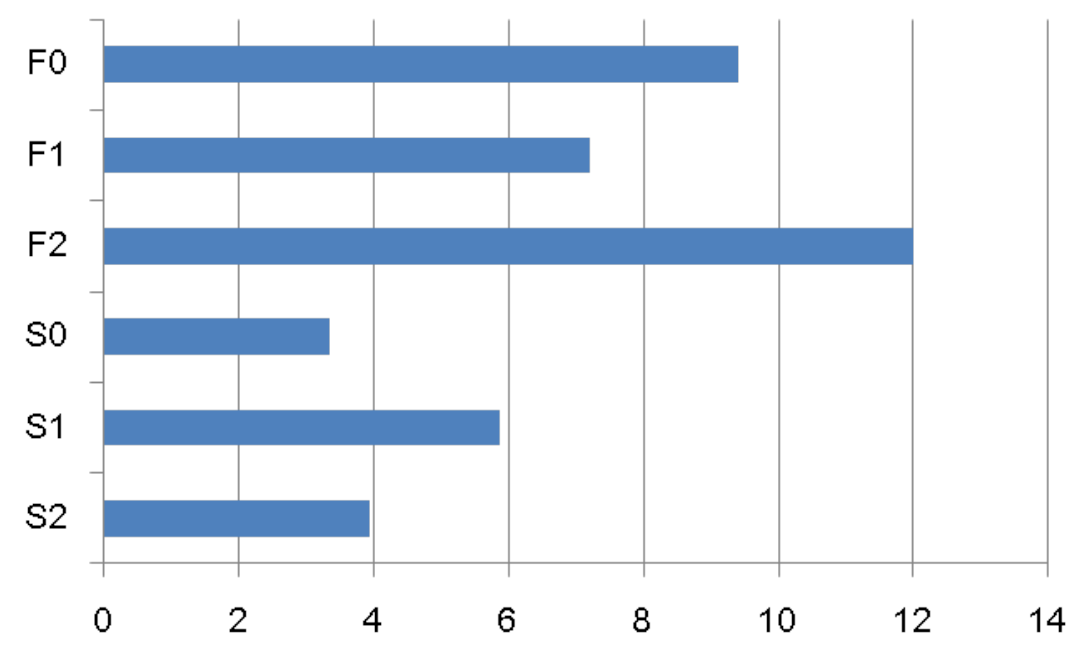

with theory: buyers are quicker when giving feedback on a bad transaction. ${ }^{14}$

- Free lunch. Different bidders have different costs of providing feedback. As suggested by the results above, even when no rebate is given, a considerable fraction of buyers do provide feedback. Therefore, when the seller pays for feedback to any buyer who is willing to do so, the marginal effect of such a payment is small in the sense that only a few buyers switch from not giving feedback to giving feedback. For this reason, it might seem that obtaining those marginal feedbacks comes at a very high cost (that is, a large amount of feedback discounts are given for a small number of extra feedbacks). However, a forward looking buyer with zero feedback cost one who would give feedback regardless of the rebate - should anticipate a gain of $\$ 1$ or $\$ 2$ (as the case may be) and this anticipated gain should be reflected in his or her bid. In other words, theory would predict that the seller's cost of paying for feedback is largely recovered in the form of higher bids.

Accordingly, we now test the prediction that feedback rewards lead to

14. The average days for leaving negative and neural feedback is 4.7 , while the average days for leaving positive feedback is 11.2 in phase $2-4$. When we include all phases, the average days are 4.7 and 10.5 , respectively. 
Table 6

Feedback reward and bidding behavior

\begin{tabular}{|l|r|r|r|}
\hline Rebate (\$) & 0 & 1 & 2 \\
\hline Average price & 3.44 & 3.51 & 3.15 \\
\hline Bidder count & 3.65 & 3.82 & 3.53 \\
\hline Bid count & 5.26 & 5.53 & 4.97 \\
\hline N & 66 & 45 & 30 \\
\hline
\end{tabular}

higher bids. Table 6 shows the average price, bidder count, and number of bids for each treatment in Phases $2-4 .{ }^{15}$ The data suggests that, contrary to the theory prediction, there is not much difference in bidding behavior resulting from rebate promises.

A related research question pertains to the number of bidders. Again, Table 6 suggests that feedback rebates have no effect.

There are several interpretations for this absence of an effect. One is that buyers are myopic, in the sense that at the time of bidding they do not take into account the future saving provided by the feedback rebate. An alternative explanation is that buyers are incredulous about the feedback rebate offers. Still another alternative explanation is that buyers are simply unaware of the feedback rebate promise. In the next subsection we provide evidence that helps tease out among these alternative explanations.

Show me the money. As mentioned earlier, a communications error led our RA to mistakenly offer a $\$ 1$ rebate before receiving feedback during an initial stage of our experiment. We denoted this phase as Phase 1 and decided not to use it for our statistical tests (to the extent that we are interested in the effect of conditional feedback rebates). However, we decided this was a good opportunity to "turn lemons into lemonade:" our unintentional mistake provides a test of whether or not the conditionality of the feedback rebate (on actually receiving feedback) plays a role.

Both Phases 1 and 2 contain 60 fast-shipping transactions. In both cases we have 12 transactions with no feedback and the remaining 48 with positive feedback. In other words, in terms of frequency and type of feedback the two phases are identical: the conditionality of feedback seems to have no effect on incentives to give feedback. Moreover, restricting to the 48 transactions when feedback was given, we observe that the mean number of

15. The results do not change if we include Phase 1's data as well. 
days before feedback is given is lower when the rebate is given after feedback. Specifically, we use a one tail t-test and $\operatorname{Pr}(T>t)=0.0610$.

Together, these results suggest that incentives do not seem to play an important role, either because buyers are unaware or incredulous about the seller's offer, or because reciprocity considerations play a bigger role than economic incentives. According to Bénabou and Tirole (2003),

A central tenet of economics is that individuals respond to incentives. For psychologists and sociologists, in contrast, rewards and punishments are often counterproductive, because they undermine intrinsic motivation.

Our study suggests that the effects of conditional feedback go beyond those of economic incentives; in fact, they may primarily consist of motivational incentives.

\section{Results: regression analysis}

In this section, we turn to regression analysis. While the analysis in the previous section allows for a first glance at the statistical and economic significance of the various treatments, multivariate regression analysis has the advantage of teasing out the effects of the various explanatory variables. Moreover, by pooling the results of various treatments, we are able to work with a greater number of observations and thus perform more powerful tests.

The last subsection in the previous section suggests that our mistake of having offered the feedback rebate before feedback was received did not have much of an impact on feedback behavior. Motivated by this result, we include Phase 1 in the dataset we use for multivariate regression analysis. However, we control for phase fixed effects to allow for the possibility that there is an effect we were unable to measure in our earlier data tabulation.

We consider two sets of regressions. The first one deals with feedback behavior, while the second one deals with bidding behavior. Our results regarding feedback behavior are presented in Table 7 . The first regression looks at the effects on the rate of feedback behavior (regardless of type of feedback). The results suggest that conditional rebates have an effect that is positive but not statistically significant. The effect of slow shipping is significantly negative. Together, these results seem consistent with the idea that buyers provide positive feedback with a high rate when the seller gives

positive feedback to begin with (as we did). Further increasing the rate of positive feedback is difficult even if rebates are offered. However, lowering 


\section{Table 7}

Regression analysis of feedback behavior

\begin{tabular}{|l|l|l|l|l|l|l|}
\hline Dependent variable & $\begin{array}{l}\text { Some } \\
\text { feedback }\end{array}$ & $\begin{array}{l}\text { Positive } \\
\text { feedback }\end{array}$ & $\begin{array}{l}\text { Negative } \\
\text { feedback }\end{array}$ & $\begin{array}{l}\text { Negative } \\
\text { feedback }\end{array}$ & $\begin{array}{l}\text { Feedback } \\
(-1,0,1)\end{array}$ & $\begin{array}{l}\text { Days till } \\
\text { feedback }\end{array}$ \\
\hline Regression type & Logit & Logit & Logit & OLS & OLS & OLS \\
\hline \$1 rebate & 0.394 & 0.470 & -0.733 & -0.010 & 0.0915 & -0.633 \\
& $(0.95)$ & $(1.16)$ & $(-0.75)$ & $(-0.32)$ & $(1.11)$ & $(-0.43)$ \\
\hline \$2 rebate & 0.633 & 1.266 & -2.024 & -0.096 & $0.311^{* *}$ & 0.629 \\
& $(0.83)$ & $(1.60)$ & $(-1.30)$ & $(-1.64)$ & $(2.03)$ & $(0.23)$ \\
\hline Slow shipping & $-2.075^{* *}$ & $-2.669^{* * *}$ & 0.000 & $0.170^{* *}$ & $-0.587^{* * *}$ & $-6.792^{* *}$ \\
\hline Seller score & $(-2.22)$ & $(2.88)$ & $($ omitted) & $(2.37)$ & $(-3.14)$ & $(-2.05)$ \\
\hline Seller's perfect record & $-0.322^{* * *}$ & $-0.233^{* *}$ & 1.002 & 0.00222 & $-0.0120^{*}$ & -0.112 \\
\hline Date & $(-3.41)$ & $(-2.57)$ & $(1.33)$ & $(0.90)$ & $(-1.86)$ & $(-0.98)$ \\
\hline Seller and phase F.E. & $(0.43)$ & -0.504 & 2.402 & 0.105 & $-0.477^{* *}$ & 1.208 \\
\hline Constant & $(-0.50)$ & $(1.60)$ & $(1.46)$ & $(-2.54)$ & $(0.36)$ \\
\hline & $(3.07)$ & $(2.01)$ & $(-0.68)$ & $(0.10)$ & $(0.26)$ & 0.000345 \\
\hline$N$ & $-3109.3^{* * *}$ & $-1893.3^{* *}$ & 2148.4 & -0.509 & 0.803 & 2.062 \\
\hline Adj. $R^{2}$ & $(-3.07)$ & $(-2.00)$ & $(0.66)$ & $(-0.23)$ & $(0.14)$ & $(0.02)$ \\
\hline Pseudo $R^{2}$ & 201 & 201 & 51 & 201 & 201 & 201 \\
\hline & & & & 0.125 & 0.168 & 0.030 \\
\hline
\end{tabular}


the quality of a transaction does have the effect of decreasing the buyers' propensity to give (positive) feedback. The first regression also suggests that the seller's eBay score (number of positive feedbacks previously received) has a negative effect on the likelihood of receiving feedback. We have no clear explanation why this is the case. One possibility is that the buyer internalizes the fact that feedback is more valuable to less experienced sellers. Finally, time has a positive effect on feedback giving, which possibly reflects a behavioral trend on eBay.

In the second regression we look specifically at positive feedback. The results suggest that the effect of conditional rebates is greater than when we consider any form of feedback. However, the statistical significance of the coefficients is marginal at best. The $p$ value for the $\$ 2$ rebate variable is $11 \%$. The results also confirm that lower quality transactions lead to less positive feedback. We continue to observe a negative effect of the sellers historical store and a positive effect of time.

In the third and forth regressions, we look at the determinants of negative feedback. Following previous evidence that neutral feedback is commonly interpreted as negative, we pool neutral and negative feedbacks into one single category, which we call "negative." 16 The third regression, like the first two ones, uses a logit model. The coefficient of slow shipping cannot be estimated: recall that there are only negative feedback messages when slow shipping is turned on. In order to obtain an idea of the effect of slow shipping, we use an OLS model instead (fourth regression). Although the standard error estimates are not unbiased, the results suggest nevertheless that slow shipping is an important determinant of negative feedback. This is not surprising, and it shows that feedback is not purely arbitrary, that is, it has informational content. It is also interesting to observe that the coefficient on a $\$ 2$ conditional rebate is negative and significant (both statistically and economically). This suggests that conditional feedback rebates can be a form of "buying" silence from disgruntled buyers.

In the fifth regression we consider a dependent variable, Feedback, which is defined as follows. If the feedback is positive, then Feedback=1. If the feedback is negative or neutral, then Feedback $=-1$. Finally, if no feedback is given then Feedback=0. This regression allows us to detect biases in the nature of feedback. Consistently with the previous regression, the coefficient on slow shipping and negative (and statistically significant): buyers' feedback reflects transaction quality. However, we also observe a positive (and statistically significant) coefficient on the $\$ 2$ rebate variable. This suggests

16. See for example Cabral and Hortaçsu (2010). 
Table 8

Regression analysis of bidding behavior (all OLS regressions)

\begin{tabular}{|l|l|l|l|}
\hline Dependent variable & Price & $\begin{array}{l}\text { Number of } \\
\text { bidders }\end{array}$ & $\begin{array}{l}\text { Number of } \\
\text { bids }\end{array}$ \\
\hline \$1 rebate & -0.00536 & -0.0550 & -0.0226 \\
& $(-0.02)$ & $(-0.27)$ & $(-0.07)$ \\
\hline \$2 rebate & 0.178 & 0.154 & -0.103 \\
& $(0.47)$ & $(0.46)$ & $(-0.18)$ \\
\hline Slow shipping & 0.525 & 0.486 & $1.646^{* * *}$ \\
& $(1.41)$ & $(1.48)$ & $(3.01)$ \\
\hline Seller score & $-0.0387^{* * *}$ & $-0.0274^{* * *}$ & $-0.0540^{* * *}$ \\
\hline Seller's perfect record & $(-5.32)$ & $(-4.27)$ & $(-5.07)$ \\
\hline Date & 0.0389 & 0.177 & 0.722 \\
& $(0.08)$ & $(0.43)$ & $(1.05)$ \\
\hline Seller F.E. & 0.000521 & 0.000154 & 0.000454 \\
\hline Constant & $(1.30)$ & $(0.44)$ & $(0.77)$ \\
\hline N & $\mathrm{Y}$ & $\mathrm{Y}$ & $\mathrm{Y}$ \\
\hline Adj. $R^{2}$ & -13.11 & 0.511 & -7.978 \\
\hline & $(-0.82)$ & $(0.04)$ & $(-0.34)$ \\
\hline
\end{tabular}

that conditional feedback rebates not only influence the rate of feedback but also the nature of feedback, biasing it towards positive feedback.

Finally, the sixth regression looks at the determinants of speed of feedback. This regression suggests that buyers leave feedback quicker for slowshipping transactions than for fast-shipping transactions. This confirms our observations in the previous section.

We next turn to the second set of regressions, the results of which are reported in Table 8. Differently from the previous set of regressions, we do not include phase fixed effects. In particular, the fact that feedback was (mistakenly) given before feedback was received (in Phase 1) should have no effect on bidding behavior. We do keep, however, seller fixed effects.

The first regression looks at the determinants of sale price. Contrary to theory (and in accordance with the earlier tabulation results) we see that feedback rebates have no significant effect on price. The regression coefficients have the right sign but are not statistically significant. We do observe, however, a very significant negative coefficient on the variable seller score, similarly to the first set of equations. In this case, the sign of the coefficient 


\section{Figure 5}

Outcome percentages per treatment

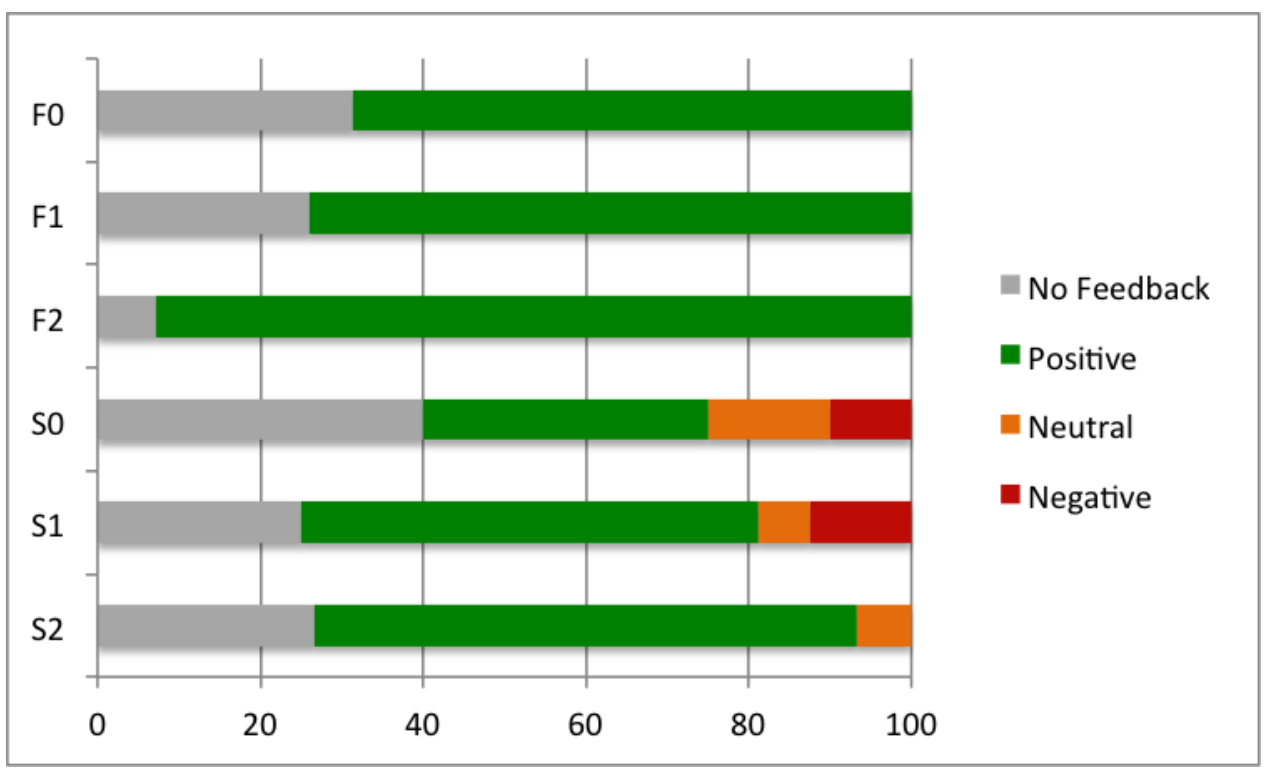

is particularly striking as standard reputation theories would predict it to be positive. The coefficient of the variable "Seller perfect score," which theory would predict to have a positive sign, is not significantly different from zero (and has a negative sign).

A similar pattern is observed in the second and third regressions, where the only statistically significant coefficient is that of seller score and with a negative sign. Since the seller score steadily increases over time, one might think that this variable is measuring something else than the buyers' estimate of the seller's value. However, we include the calendar date in all regressions and this variable seems not to be significant. The negative effect of seller score remains a puzzle to us.

\section{Discussion and concluding remarks}

Figure 5 summarizes the main results in the paper. The top three treatments correspond to fast shipping transactions. As can be seen, all feedback received was positive. In this context, paying for feedback is effectively paying for positive feedback. The figure suggest that, the more we pay for feedback, the more likely (positive) feedback is received. However, to the extent 
that the probability of (positive) feedback is large to begin with, paying for feedback does not have a very significant effect on the outcome. In a sense, providing a good service - and offering the buyer positive feedback, as we did - is a good substitute for paying for feedback.

Things change as we move to the slow shipping treatments (the bottom three treatments in Figure 5). Now we observe negative and neutral feedback (both of which we treat as negative feedback). The effect of paying for feedback is now two-fold: it decreases the number of negative feedbacks and increases the number of positive feedbacks. The net result on the total number of feedbacks is positive but small.

Whereas treatments F0-F2 might suggest that buyers are being paid for the cost of giving feedback, treatments S0-S2 clearly suggest that paying for feedback alters the nature of feedback: disgruntled buyers are silenced by a feedback rebate, even though we explicitly state that the rebate is conditional on giving feedback, not on giving a particular form of feedback.

All in all, our results suggest that it is possible to increase the feedback rate by means of giving conditional feedback rebates. However, this is a rather costly means of obtaining feedback. Moreover, it is likely that the nature of feedback will be considerably affected by rebates: you can buy feedback but you cannot buy unbiased feedback. 


\section{References}

Abeler, Johannes, Juluana Calaki, Kai Andree and Christoph Basek (2010), "The power of apology," Economics Letters 107, 233-235.

Ariely, Dan, Anat Bracha, And Stephan Meier (2009), "Doing Good or Doing Well? Image Motivation and Monetary Incentives in Behaving Prosocially," American Economic Review 99 (1), 544-555.

Avery, Christopher, Paul Resnick, and Richard Zeckhauser (1999), "The Market for Evaluations," American Economic Review 89 (3), 564-584.

Bajari, PAtrick And Ali Hortacsu (2004), "Economic insights from internet auctions," Journal of Economic Literature 42, 457-486.

BÉnabou, Roland And Jean Tirole (2003), "Intrinsic and Extrinsic Motivation," The Review of Economic Studies 70 (3), 489-520.

Bolton, Gary E., Elena Katok, And Axel Ockenfels (2004), "How Effective Are Electronic Reputation Mechanisms? An Experimental Investigation," Management Science 50 (11), 1587-1602.

Brown, Jennifer, And John Morgan (2006), "Reputation in Online Markets: The Market for Trust," California Management Review 49 (1), 61-81.

Brown, Jennifer, Tanjim Hossain, And John Morgan (2010), "Shrouded Attributes and Information Suppression: Evidence from Field Experiments," Quarterly Journal of Economics 125 (2), 859-876.

Cabral, Luís (2012), "Reputation on the Internet," in Peitz and Waldfogel (Eds), The Oxford Handbook of the Digital Economy, Oxford University Press.

Cabral, Luís, And Ali Hortaçsu (2010), "The Dynamics of Seller Reputation: Theory and Evidence from eBay," Journal of Industrial Economics 58, 5478.

Chen, Yan, Max Harper, Joseph Konstan and Sherry Xin Li (2010a), "Social Comparisons and Contributions to Online Communities: A Field Experiment on MovieLens," American Economic Review 100 (4), 1358-1398.

Chen, Yan, Teck-Hua Ho And Yong-Mi Kim (2010b), "Knowledge Market Design: A Field Experiment on Google Answers," Journal of Public Economics Theory 12 (4), 641-664.

Dellarocas, Chrysanthos (2003), "The Digitization of Word of Mouth: Promise and Challenges of Online Feedback Mechanisms," Management Science 49 (10), 1407-1424. 
Dellarocas, Chrysanthos, and Charles A. Wood (2008), "The Sound of Silence in Online Feedback: Estimating Trading Risks in the Presence of Reporting Bias," Management Science 54 (3), 460-476.

De Quervain, Dominique J.-F., Urs Fischbacher, Valerie Treyer, Melanie Schellhammer, Ulrich Schnyder, Alfred Buck, and Ernst Fehr (2004), "The neural basis of altruistic punishment," Science 305, 1254C1258.

Fehr, Ernst, And Simon Gächter (2000a), "Cooperation and Punishment in Public Goods Experiments," American Economic Review 90 (4), 980-994.

Fehr, Ernst, and Simon Gächter (2000b), "Fairness and Retaliation: The Economics of Reciprocity," Journal of Economic Perspective 14 (3), 159181.

Grosskopf, Brit, And Rajiv Sarin (2010), "Is Reputation Good or Bad? An Experiment," American Economic Review 100 (5), 2187-2204.

Houser, Daniel, And John Wooders (2006), "Reputation in auctions: Theory and evidence from eBay," Journal of Economics and Management Strategy 15 (2), 353-369.

Jin, Ginger, And Andrew Kato (2006), "Price, Quality and Reputation: Evidence from An Online Field Experiment," RAND Journal of Economics 37 $(4)$. .

Jurca, Radu, And Boi Faltings (2007), "Collusion resistant, incentive compatible feedback payments," In Proceeding of the 8th ACM conference on Electronic commerce, 200-209. New York: The Association for Computing Machinery.

Li, Lingfang (Ivy) (2010a), "Reputation, Trust, and Rebates: How Online Auction Markets Can Improve Their Feedback Mechanisms," Journal of Economics and Management Strategy 19 (2), 303-331.

Li, Lingfang (Ivy) (2010b), "What is the Cost of Venting? Evidence from eBay," Economics Letters 108, 215-218.

Li, Lingfang (Ivy), and Erte XiaO (2010), "Money Talks? An Experimental Study of Rebate in Reputation System Design," Working Paper.

Miller, Nolan , Paul Resnick, and Richard Zeckhauser (2005), "Eliciting Honest Feedback: The Peer Prediction Method," Management Science $\mathbf{5 1}$ (9), 1359-1373.

Resnick, P., R. Zeckhauser, J. Swanson, and L. Lockwood (2006), "The Value of Reputation on eBay: A Controlled Experiment," Experimental Economics 9, 79-101. 
Shapiro, Carl (1983), "Premiums for High Quality Products as Returns to Reputations," The Quarterly Journal of Economics 98 (4), 659-680.

Sobel, Joel (forthcoming), "Signaling Games," in Encyclopedia of Complexity and System Science, M. Sotomayor(ed.), Springer.

Xiao, Erte, and Daniel Houser ( 2005), "Emotion expression in human punishment behavior," Proceedings of the National Academy of Sciences of the United States of America 102 (20), 7398-7401.

Wang, Zhongmin (2010), "Anonymity, Social Image, and the Competition for Volunteers: A Case Study of the Online Market for Reviews," The B.E. Journal of Economic Analysis and Policy 10 (1), (Contributions), Article 44. 